\title{
O lugar do patrimônio documental: Brasília e Fundo NovaCap
}

\author{
Renato Crivelli ${ }^{I}$ \\ https://orcid.org/0000-0003-3970-5262 \\ Maria Leandro Bizello ${ }^{I I}$ \\ ${ }^{I}$ Universidade Estadual Paulista, Marília, SP, Brasil. \\ Professor do Departamento de Arquivologia da Universidade Federal \\ do Estado do Rio de Janeiro (UNIRIO). \\ II Universidade Estadual Paulista, Marília, SP, Brasil. \\ Professora do Departamento de Ciência da Informação e do Programa \\ de Pós-graduação em Ciência da Informação da Universidade Estadual \\ Paulista - Campus de Marília.
}

http://dx.doi.org/10.1590/1981-5344/3288

O presente artigo discute os patrimônios documentais como uma apresentação do universo patrimonial ainda pouco explorada, o que pode trazer questionamentos tanto à sua legitimidade quanto ao seu papel neste contexto. Uma relação mais próxima entre os patrimônios documentais e a sociedade é ponto fundamental, mas que se encontra nebulosa, seja em sua prática, seja em sua teoria. A partir desse debate, estudamos dois casos integrantes legais de Listas do Patrimônio: Brasília, como Patrimônio Mundial e o Fundo NovaCap, como Patrimônio Documental, refletindo sobre o lugar dos documentos no contexto patrimonial.

Palavras-chaves: Patrimônio Documental; Patrimônio; Brasília; Fundo NovaCap

\section{The place of documentary heritage: Brasília and Novacap Fond}

This article discusses the documentary heritage as a presentation of the patrimonial universe still negligibly 
explored, which can bring inquiries about its legitimacy as well as its role in this context. A closer relation between the documentary heritage and the society is a fundamental, but finds itself unclear, be it in its practice, or in its theory. From this debate, we studied two cases that legally integrate the Heritage Lists: Brasilia as a World Heritage, and the NovaCap Fond as Documentary Heritage, reflecting about the place of documents in the patrimonial context.

Word-Keys: Documentary Heritage; Heritage; Brasília; NovaCap Fond

\section{Introdução}

O século $X X$ e começo do século $X X I$ têm presenciado um desenvolvimento de intenções protetivas direcionadas aos chamados patrimônios históricos e culturais. Muito se tem feito para proteger aqueles bens considerados importantes para a história e cultura das coletividades. Do mesmo modo, novos bens têm sido criados em homenagem a acontecimentos marcantes.

Várias são as formas de justificar essa efervescência patrimonial surgida durante o século XX. Castriota (2009) sugere que uma das causas dessa condição de massificação dos patrimônios está na globalização. Vista atualmente como um desenvolvimento na economia, no mercado, na política e na tecnologia, a globalização é, antes disso, uma aproximação entre os diversos grupos do planeta.

Além de benefícios econômicos, esta aproximação garante também a possibilidade de desenvolvimento cultural. $O$ acesso a elementos de culturas distantes nunca foi tão facilitado quanto atualmente. As possibilidades proporcionadas pelos desenvolvimentos nas áreas de tecnologias de comunicação permitem que longas distâncias sejam superadas em segundos.

O que tem acontecido, diz Castriota (2009, p. 23), é que este movimento vem "[...] se mostrar catastrófico, com a destruição e o apagamento de uma cultura pela outra". Nesse sentido, a globalização assume a forma de um fenômeno prejudicial à cultura, às tradições e às características específicas de cada grupo ou coletividade, onde podemos incluir, até mesmo, nações.

O autor relembra um acontecimento bastante próximo da nossa realidade ao comentar a respeito do contato de tribos indígenas americanas com povos europeus. Os ameríndios foram levados a adotar hábitos e costumes europeus, até então estranhos aos seus costumes e estilo de vida tradicionais. De modo violento, este contato, ao invés de contribuir para o enriquecimento de ambas as culturas, no sentido de tomarem conhecimento da existência de outros povos com hábitos, 
costumes e organização diferenciados, proporcionou uma sobreposição da cultura europeia em relação à cultura tribal.

Outro exemplo ilustrativo e mais atual encontra-se na adoção do chamado American Way of Life. Os costumes de vida norte-americanos estão cada vez mais disseminados, e passam a cobrir, por vezes, costumes tradicionais das culturas afetadas por esta novidade. Exemplos desta exposição estão presentes nos mais variados espaços do cotidiano, de roupas e acessórios comuns aos estrangeiros, às tecnologias, passando por comidas e músicas. Acontecimentos deste porte são uteis para mostrar a contribuição contraditória da globalização.

Em meio a este conjunto de acontecimentos, permeado por disputas e conflitos - mesmo que tácitos - entre culturas múltiplas, torna-se urgente o desenvolvimento de estratégias destinadas à afirmação da cultura e da identidade próprias frente à invasão massificadora de informações e eventos externos.

\section{Patrimônio como legislação e como mentalidade}

Nesse sentido, os patrimônios podem se mostrar como estratégia de sobrevivência em cenários de sobreposições culturais. Eles serão entendidos como o extrato das culturas dos povos, dispostos de forma que possam preservá-las e disseminá-las. Françoise Choay (2001, p. 11) reflete sobre patrimônios históricos:

A expressão designa um bem deixado ao usufruto de uma comunidade que ampliou a dimensões planetárias, constituído pela acumulação contínua de uma diversidade de objetos que se congregam por seu passado comum: obras e obras-primas das belas artes e das artes aplicadas, trabalhos e produtos de todos os saberes e savoir-faire dos seres humanos. Em nossa sociedade errante, constantemente transformada pela mobilidade e ubiquidade de seu presente, 'patrimônio histórico' tornou-se a palavra-chave da tribo midiática. Ela remete a uma instituição e a uma mentalidade.

Choay (2001) ainda traça um histórico das formas de compreensão destes patrimônios ao longo da história, retomando ao Quattrocento e ao período dos antiquários, de modo que nos permita compreender como a concepção do termo se ampliou ao longo dos séculos.

José Reginaldo Gonçalves (2009) lembra que muitos estudos na área apontam o surgimento da ideia de patrimônio no contexto da Revolução Francesa, no final do século XVIII. No entanto, a noção de patrimônio como uma mentalidade é mais antiga e percorre todo o desenvolvimento das civilizações. O que há nesse período de crise política e social na França é o surgimento de legislações protetivas direcionadas aos patrimônios.

Vemos, portanto, que há a oficialização de uma instituição já existente que passa a ser regida por leis específicas. Nesse sentido, Thiesen (2013, p. 27) analisa as instituições: 
Vistas através das lentes do tempo, as instituições refletem as formalizações das culturas, daquilo que as diferentes sociedades cultivam como maneiras de pensar: hábitos, usos, costumes, comportamentos, etc. Aquilo que instituem. Todo esse percurso nas esferas da vida social tem deixado vestígios das mais variadas ordens. Visíveis ou invisíveis, os produtos da experiência do homem em sociedade também constituem legados/memórias.

A noção de instituição está no cerne da prática de patrimônio, ainda que de modo tácito. As legislações surgem para atender a uma demanda de proteção sobre algo já instituído. Podemos dizer que as legislações patrimoniais surgidas após a Revolução Francesa proporcionam uma adequação do patrimônio às instituições sociais do Estado Moderno que surge naquele momento.

A partir daí, as legislações buscaram promover adequações de modo que atendessem a todos os tipos de patrimônios, dentro de uma lógica classificativa de categorias que seguem o pensamento moderno. Patrimônio, hoje, congrega uma gama de divisões como nunca se viu (GONÇALVES, 2009).

Podemos observar o caso das legislações brasileiras dedicadas a este fim. Evidencia-se, num curto período, a reorganização do entendimento oficial de patrimônio por meio das Constituições Federais. $\mathrm{Na}$ Constituição Brasileira de 1934, artigo 148, encontramos que cabe à União, aos Estados e Municípios "[...] proteger os objetos de interesse histórico e o patrimônio artístico do País [...]" (BRASIL, 1934). Vemos aqui uma descrição demasiadamente sucinta, capaz de atingir proporções muito amplas.

Em 1988, com a aprovação da Constituição Brasileira vigente, podemos notar considerável desenvolvimento no entendimento que se tem de patrimônio nacional e, principalmente, uma visão ampliada de sua composição. Encontramos no artigo 216 a seguinte descrição:

Constituem patrimônio cultural brasileiro os bens de natureza material e imaterial, tomados individualmente ou em conjunto, portadores de referência à identidade, à ação, à memória dos diferentes grupos formadores da sociedade brasileira, nos quais se incluem:

I - as formas de expressão;

II - os modos de criar, fazer e viver;

III - as criações científicas, artísticas e tecnológicas;

IV - as obras, objetos, documentos, edificações e demais espaços destinados às manifestações artístico-culturais;

$\mathrm{V}$ - os conjuntos urbanos e sítios de valor histórico, paisagístico, artístico, arqueológico, paleontológico, ecológico e científico. (BRASIL, 1988)

Vemos, com essa comparação, o desenvolvimento da noção legal que se tem de patrimônio no Brasil, de modo que encontramos na Constituição vigente a amplitude mais próxima do conceito estudado por 
Choay (2001), no qual se inclui grande parte dos produtos e fazeres dos homens.

Outro ponto de convergência entre a Constituição Brasileira e os dizeres de Choay se encontra no fato de ser o corpus do patrimônio uma acumulação destes bens culturais, o que pode nos levar a uma noção de colecionamento. Gonçalves (2009, p. 28) levanta essa questão e diz que "A categoria 'colecionamento' traduz, de certo modo, o processo de formação de patrimônios", e acrescenta que "Todo e qualquer grupo humano exerce algum tipo de atividade de colecionamento de objetos materiais, cujo efeito é demarcar domínio subjetivo em oposição ao 'outro'. O resultado dessa atividade é precisamente a constituição de um patrimônio".

Gonçalves diz ser o efeito deste ato o estabelecimento de domínios subjetivos em relação a outros, tornando este conjunto colecionado uma forma de identificar limites entre indivíduos e entidades. É com base nestes mesmos limites que se afirmarão as identidades desta coletividade.

Neste trabalho de delimitação de identidade, a alteridade é um fator fundamental a se considerar como forma da própria autoafirmação. O processo de estabelecimento de uma identidade social é dependente de um processo de negociações subjetivas entre o que pretende estabelecer sua identidade e todos os que o cercam. Vários podem ser os critérios utilizados para que se estabeleça essa condição. Michel Pollak (1992, p. 204) entende que "A construção da identidade é um fenômeno que se produz em referência aos outros, em referência aos critérios de aceitabilidade, de admissibilidade, de credibilidade, e que se faz por meio da negociação direta com outros".

Integra-se ainda, como fator colaborativo deste empreendimento de construção da identidade, a necessidade de uma memória coletiva do grupo, que servirá como pilar de sustentação da imagem e do discurso apresentados pelo grupo. A memória coletiva de uma organização social é tão relevante no sentido de se trabalhar sua identidade que deverá, necessariamente, ser mantida ativa, transmitida e retransmitida por várias gerações. Para que isso ocorra, é importante que esta memória seja uma entidade autêntica, e que conte com a devoção de todos os membros do grupo social.

Maurice Halbwachs (1990) vem nos dizer da memória nacional como a memória coletiva melhor trabalhada, em comparação às memórias de grupos menores. A força de sua autenticidade leva os integrantes do grupo a interligarem a memória coletiva como suas memórias individuais. É justamente este o objetivo que se pretende no empreendimento da construção da identidade e da memória do grupo.

O sentimento de pertencimento por parte de seus integrantes mostra que a imagem é sólida, que a memória é consistente e que é entendida como uma forma de parametrizar as lembranças dos indivíduos. Nesse sentido Halbwachs (1990) nos diz que a memória individual se sustenta pela memória coletiva.

Sendo a identidade criada em um contexto de disputas culturais, o patrimônio como instituição não pode deixar de ser uma emanação de 
poder. Enquanto um ato de colecionamento, a determinação do que se guardará é um ato político. Como diz Chagas (2002, p. 139)

todo projeto de preservação patrimonial resulta de exercício do poder, ainda que, em muitos casos, a sua justificativa seja apresentada em nome do perigo de destruição ou de hipotéticos valores que todos devem acatar e reconhecer.

Da mesma forma, é necessário que haja um trabalho de organização destes elementos de memória e identidade, de modo que se apresentem como um cenário completo, compreensível, coeso e autêntico. Este trabalho de organização é entendido por Gonçalves (1996), como "narrativas nacionais". Estas são elaboradas com o objetivo de construção de um discurso nacionalista imbuído de um poder de convencimento que apela não apenas para a dimensão cognitiva, mas, principalmente, para a "dimensão afetiva", em busca de atender a um "evanescente sentimento de ser".

Estes fatores, entrelaçados por uma elaborada narrativa histórica, serão os responsáveis por sustentar a apresentação que se faz da cultura e das tradições de um povo. Este será o resultado de um esforço que pautará a delimitação e os critérios de colecionamento de seus representantes - os patrimônios culturais.

\section{0 consumo do patrimônio pela sociedade moderna}

Além dos fatores apontados, que definem e sustentam o sistema patrimonial, existe na sociedade moderna a necessidade de consumo dos bens patrimoniais, ou seja, não basta identificá-los, preservá-los e conservá-los, mas consumi-los de alguma forma. Para tanto, os poderes públicos utilizam como justificativa a valorização do patrimônio cultural, no sentido de torná-los úteis à sociedade de modo geral: o ideal de disseminação das identidades e memórias do grupo.

Nesse sentido, em 1967, a Organização dos Estados Americanos (OEA), realizou a Reunião sobre conservação e utilização de monumentos e lugares de interesses históricos e artísticos, em Quito, no Equador, cujo relatório final foi divulgado com o nome "Normas de Quito" (OEA, 1967). Dentre os assuntos tratados, com o objetivo de valorizar os monumentos históricos mundiais, o tema que se destacou foi o chamado "turismo cultural".

O relatório de Quito foi elaborado com o objetivo de indicar caminhos para a valorização do patrimônio cultural das Nações, de modo que esta atividade estivesse alinhada diretamente com o desenvolvimento local. O turismo cultural seria utilizado como meio para este desenvolvimento.

Sob a égide do pensamento de demarcação de territórios étnicos e ideológicos, o sistema do turismo cultural pode se mostrar como algo benéfico à Nação que pretende se mostrar às demais nacionalidades, como aponta Rodrigues (2002, p. 19), analisando o caso brasileiro: 
A valorização turística do patrimônio já se mostrara eficiente em outros países e, além disso, possibilitava a manipulação de um universo simbólico de considerável importância para o reforço do civismo. A propaganda dos 'monumentos históricos', juntamente com a das 'festas típicas' e das 'belezas naturais', poderia promover aos olhos do mundo, e dos brasileiros, a imagem de um país com tradição e potencialidade para enfrentar o futuro.

A divulgação da imagem do país para os "outros", por meio de seus patrimônios, os eleva a uma escala além da intenção de preservação da memória coletiva e de disseminação e fortalecimento do sentimento de pertencimento de seus integrantes. Há aí um fator relevante, já previsto desde a intenção de preservação destes bens: servirem como importante ferramenta política das forças de poder nacionais.

Com este pensamento, os patrimônios passam a ser vistos não pelos olhos da sociedade de base, mas pelos poderes que regem essa sociedade, como um instrumento que deve ser valorizado e utilizado por deter, em seu cerne, influências ideológicas e políticas.

Além disso, há outro fator que colabora para o investimento na preservação destes locais. Ainda como uma forma de uso com intenções bem definidas, o turismo cultural é muito valorizado por ser considerado uma fonte de recursos financeiros e de movimentação econômica.

Rodrigues (2002) diz que essa intenção econômica sustentada pelos poderes é muitas vezes mascarada sob o argumento da custosa manutenção destes bens. Muito alta aos cofres públicos, as quantias arrecadadas na exploração dos bens serão revertidas ao sustento do mesmo. Encontramos no relatório de Quito, em seu item VII- Os monumentos em função do turismo, uma afirmação que ilustra esta situação:

Tudo quanto contribuir para exaltar os valores do espírito, mesmo que a intenção original nada tenha a ver com a cultura, há de derivar em seu benefício. A Europa deve ao turismo, direta ou indiretamente, a salvaguarda de grande parte de seu patrimônio cultural, condenado à completa e irremediável destruição, e a sensibilidade contemporânea, mais visual do que literária, tem oportunidade de se enriquecer com a contemplação de novos exemplos da civilização ocidental, resgatados tecnicamente graças aos poderosos estímulos turísticos (OEA, 1967, p. 6-7).

Esta função investida aos patrimônios é diretamente relacionada à intenção de desenvolvimento regional suscitada pelo mesmo relatório. A frequência de turistas sempre se apresenta com disposição a contribuir com a movimentação econômica do local. Isto gerará as bases necessárias para que se consolide o objetivo de desenvolvimento regional estipulado e previsto pela comunidade preservacionista.

No entanto, Veloso (2006) denuncia uma situação à qual devemos atentar. A autora adverte sobre o risco iminente de transformação do patrimônio cultural em um fetiche, ligado diretamente ao sentido comercial e mercadológico da palavra. Veloso enfatiza o risco sob a condição de ocorrer um "deslocamento simbólico", onde o comércio é 
realizado através de coisas transmutadas em outras coisas, sendo que, na verdade, comercializa-se com um ideal que não pertence a essa coisa. No caso do patrimônio, "alguma manifestação de um passado significativo para um presentismo vazio" (VELOSO, 2006, p. 441).

De modo geral, ao analisarmos as recomendações da reunião de Quito, vemos sentido nas ideias levantadas por Veloso, ao pensarmos que, sob a égide argumentativa da preservação e utilização valorativa dos patrimônios, busca-se, concomitantemente, o desenvolvimento econômico e social regional. Tal prática vem se mostrar, antes e muito mais, como exemplo e prática de fetiche mercadológico do que divulgação cultural ou simbólica dos bens. Assim, simbólica mesmo será a sensação de fruição e interação por parte dos turistas que visitam os lugares de estimado interesse histórico.

A manifestação de Quito nos dirá o contrário:

Os valores propriamente culturais não se desnaturalizam nem se comprometem ao vincular-se com os interesses turísticos e, longe disso, a maior atração exercida pelos monumentos e a fluência crescente de visitantes contribuem para afirmar a consciência de sua importância e significação nacionais (OEA, 1967: 6).

Note-se que o indicado e recomendado para a apresentação e representação da cultura aos "outros" são os patrimônios materializados na condição de lugares. Tal observação nos sinaliza que os bens culturais de ordem bibliográfica e documental não são relacionados como instrumentos de apresentação ou exibição nas intenções patrimoniais, tanto as destinadas a outros povos, quanto aos próprios membros do grupo.

Podemos entender esse aquinhoamento de funções e de bens patrimoniais como uma adequação aos costumes da sociedade moderna. Nos foi dito pelo relatório de Quito, em uma citação utilizada acima, que "a sensibilidade contemporânea, mais visual do que literária, tem oportunidade de se enriquecer com a contemplação de novos exemplos da civilização ocidental" (grifo nosso).

Podemos compreender esta colocação das Normas de Quito como um estímulo ao trabalho de investimento direcionado aos bens com efeitos visuais. O visual/estético é capaz de promover um contato mais imediato ${ }^{1}$ com o público se comparado a objetos que demandem leitura ou mesmo interpretação. Neste sentido, notamos a validade do alerta dado por Veloso, com um risco iminente de sobreposição dos valores de culto e de exposição em relação aos sentidos simbólico, histórico e social necessariamente presente nos bens culturais.

O estímulo ao turismo cultural manifesto no documento final da reunião de Quito insere o patrimônio nacional na lógica do consumo perverso. Nesse sentido, qualquer política patrimonial nacional elege os bens que devem ser visitados e explorados economicamente. $O$ bem patrimonial deve ter não só representatividade do grupo nacional, mas

${ }^{1}$ Imediato em sentido temporal, pois o contato com o bem, neste caso, será sempre mediado e mesmo mediatizado. 
apelo para ser consumido pelo estrangeiro a partir de uma série de souvenires atraentes aos visitantes. Por esta razão, em muitas edificações históricas - sobretudo em museus -, os visitantes são quase inevitavelmente dirigidos às lojas para a compra de fragmentos daquilo que já viram e apreciaram.

Partindo destes pensamentos, Lage (2002, p. 13) nos coloca uma questão fundamental: "O que é útil para proteger é o melhor meio para conhecer?".

\section{0 lugar do patrimônio documental}

O conceito de patrimônio documental ainda não se encontra bem definido, seja em âmbito científico, legal ou prático. A legislação brasileira sobre patrimônios culturais abarca os documentos como integrantes deste universo, pela primeira vez, na Constituição de 1946, onde é discriminado o termo "documentos" como um dos itens de valor histórico que devem ser protegidos pela legislação patrimonial nacional.

Anterior a isso, a legislação brasileira conta com o Decreto-Lei No 25, de 30 de novembro de 1937, que "Organiza a proteção do patrimônio histórico e artístico nacional" (BRASIL, 1937). Em seu artigo 10, determina:

Constitui o patrimônio histórico e artístico nacional o conjunto dos bens móveis e imóveis existentes no país e cuja conservação seja de interesse público, quer por sua vinculação a fatos memoráveis da história do Brasil, quer por seu excepcional valor arqueológico ou etnográfico, bibliográfico ou artístico. (grifo nosso)

Nesta definição consta o termo "bibliográfico", que pode ser atrelado a "documental"2. No entanto, é ressaltada, neste mesmo Decreto-Lei, a necessidade de ser o objeto tombado e inscrito em um dos quatro Livros do Tombo, definidos pela própria legislação. Os quatro Livros são: Livro do Tombo Arqueológico, Etnográfico e Paisagístico; Livro do Tombo Histórico; Livro do Tombo das Belas Artes e Livro do Tombo das Artes Aplicadas.

Os materiais baseados na textualidade não são claramente direcionados a algum destes Livros do Tombo. Devemos notar que, no momento da publicação deste Decreto-Lei, o Brasil conta com uma Biblioteca Nacional responsável pela preservação do material bibliográfico publicado no país. Existe também um Arquivo Nacional, em princípio responsável pela preservação da documentação arquivística pública. Porém, Célia Reis Camargo (1999) apresenta em sua tese de doutorado o Arquivo Nacional como uma instituição desestruturada e marginalizada no contexto preservacionista brasileiro, cabendo a preservação da documentação histórica nacional ao Instituto Histórico e Geográfico Brasileiro. De certo modo, tanto o material bibliográfico quanto os documentos públicos já se encontram protegidos antes mesmo do Decreto-Lei.

\footnotetext{
2 Tomando-se por base uma visão bastante rasa, na qual se compreende o documento como estritamente textual ou gráfico, à semelhança do bibliográfico. Voltaremos a este ponto.
} 
Como já dito, o conceito de patrimônio documental não é algo que conta com muitos estudos, e sua complexidade pode ser identificada na reflexão de Lage (2002, p. 15):

O conceito de Património Documental liga-se intrinsecamente ao conceito de documento no seu duplo sentido - de recurso, logo funcional, e de significado, logo cultural -, sendo no entanto mais complexo que os conceito já de si complexos de Documento (unidade de informação), Informação (dados do conhecimento registrados) ou Fonte histórica (todo o dado procedente do passado, do recente, que tem uma realidade material e objectiva, relacionado com a actividade científica e social e historicamente produzido; testemunho original, não re-elaborado, do conhecimento do passado).

A complexidade do conceito de documento pode ser encontrada já no desenvolvimento da teoria clássica da Documentação, trazida por Paul Otlet (1936) e seguida por Suzanne Briet (1951). Passa-se a observar o documento enquanto um produto dotado de materialidade e de significado, cabendo a este último a determinação do sentido documental ${ }^{3}$ e colocando em segundo plano o tipo de suporte e a forma de apresentação deste significado - muitas coisas podem ser documento, independentemente de sua forma física. Designando ao significado papel essencial na constituição do documento, identifica-se uma relevância da informação sobre o suporte, o que nos aproxima da imaterialidade.

Na última década, muito se tem discutido a respeito do chamado patrimônio imaterial, com a intenção de preservação de elementos intangíveis das culturas. Compreendermos o destaque da informação sobre o suporte no documento poderia nos levar a introduzir o documento nestas discussões. No entanto, considerando o necessário vínculo entre a informação (imaterial) e o suporte (material) para a constituição de um documento ${ }^{4}$, deveríamos, então, tratar de "patrimônio informacional" em substituição ao "patrimônio documental".

Consideremos, agora, uma definição do historiador argentino Garcia Belsunce (1986, p. 30): "patrimônio documental é o conjunto de documentos de valor informativo produzido pelas pessoas públicas e privadas, físicas e morais de uma determinada jurisdição". O autor enquadra os patrimônios documentais na linha estrita dos documentos de arquivo históricos.

Levemos em consideração, nesta definição, a ideia do valor informativo do conjunto de documentos. Isto nos aproxima da teoria apresentada por Jean-Yves Rousseau e Carol Couture (1998), herdeiros de T. R. Schellenberg ${ }^{5}$, que compreendem os valores dos documentos de arquivo em dois sentidos: o valor primário e o valor secundário. ${ }^{6}$

\footnotetext{
${ }^{3}$ Para o desenvolvimento desta discussão, Cf. CRIVELLI; BIZELLO, 2012.

${ }^{4}$ Ortega e Lara (2010) apresentam uma síntese do desenvolvimento teórico da noção de documento capaz de mostrar as visões de materialidade do documento.

${ }^{5}$ Schellenberg publicou sua obra "Modern Archives: principles and techniques" em 1956, onde originalmente é apresentada a teoria dos valores dos documentos de arquivo.

6 Para este texto tratamos especificamente de arquivos institucionais e administrativos. A questão da patrimonialização do arquivo pessoal pode ser encontrada em CRIVELLI, 2013.
} 
O primeiro caso, de Valor Primário, diz respeito à fase vital do documento na qual ainda está em seu processo de tramitação e com potencial de uso elevado por parte de seu produtor. Neste momento, os documentos são utilizados exclusivamente de forma administrativa, para servir de suporte jurídico e de ação.

No que tange ao segundo valor dos documentos, chamado de Valor Secundário, o documento passa por uma ressignificação, ao ponto que já cumpriu com o dever que lhe foi investido no momento de sua gênese. Nesta etapa, os documentos podem ser eliminados, se não houver mais nenhum tipo de interesse sobre eles, ou podem ser retidos no arquivo permanente da instituição, onde será disponibilizado para fins de pesquisa. Seu valor agora deixa de ser exclusivamente jurídico-probatório e passa a ser informativo, de testemunho (ROUSSEAU; COUTURE, 1998, p. 117-118).

Os autores ainda dizem que "[...] só uma fraca proporção do conjunto dos arquivos de uma pessoa física ou moral (jurídica) merece a atenção necessária à conservação dos documentos que apresentam um valor secundário" (1998, p. 118). O que restar será entregue à história, tomará a função de fonte de pesquisa, onde a informação que ele preserva servirá como uma forma de contato com o passado.

Neste momento, cabe-nos perguntar: tudo o que restar deste espólio documental pode ser considerado patrimônio cultural?

Para Jacques Le Goff (2013, p. 497) "O documento é monumento"; monumento no mesmo sentido utilizado por Choay (2001), ao definir os grandiosos projetos arquitetônicos com o objetivo de lembrar, de ressaltar uma "memória viva". Ambos os autores tratam de estabelecer a etimologia da palavra "monumento" (LE GOFF, 2013, p. 486; CHOAY, 2001 , p. 17), com sua origem na palavra latina monumentun, derivativo do verbo momere, que significa lembrar, recordar, trazer à lembrança.

O historiador francês faz sua afirmação a partir do trajeto de desenvolvimento do documento, por cerca de quatro séculos: durante os séculos XVII e XVIII, em muitos registros vê-se o uso destas duas palavras, monumento e documento, como sinônimas. Diretamente relacionado com a administração pública, assim como à pesquisa histórica, os documentos dos séculos XVII e XVIII eram entendidos como incontestáveis, autênticos e, acima de qualquer suspeita, dotados de fé pública. Até o momento da publicação do tratado de Don Jean Mabillon, De re diplomática, no fim do século XVII. Este tratado veio questionar a autoridade do documento quanto à sua autenticidade, o que levou os historiadores da época a buscar, então, uma historiografia mais científica (LE GOFF, 2013).

$O$ autor sugere ainda que 0 apogeu do documento sobre 0 monumento será dado apenas no final do século XIX e início do século $X X$, com o início da historiografia positivista, responsável por trabalhar com a crítica ao documento a fim de garantir a extração de todo seu potencial informativo através de sua principal característica, o elemento textual.

Mas o sentido de documento passará por uma reformulação na mentalidade historiográfica, passando ele a ser compreendido como 
qualquer elemento capaz de transmitir informações históricas e auxiliá-los no empreendimento de conhecer o passado. Começaram, então, a trabalhar com os demais formatos informativos, como a imagem, o som, ou qualquer outra apresentação sígnica além do escrito (LE GOFF, 2013).

Com a análise de Jacques Le Goff podemos compreender a proximidade na relação existente entre o documental e o monumental, no sentido de rememorar, apresentar e transmitir o passado para futuras gerações, o que nos aproxima, também, do entendimento de patrimônio cultural.

A preocupação efetiva com a preservação do patrimônio documental contou com um grande aliado apenas recentemente, durante a década de 1990, quando a United Nations for the Education, Science and Culture Organization (UNESCO) colocou em prática o Programa Memória do Mundo $\left(\mathrm{MOW}^{7}\right)$. Com o objetivo de identificar, registrar e nominar os conjuntos documentais de interesse para a preservação da memória coletiva, o Programa atua em três níveis territoriais: o nacional, o regional e o mundial. Os acervos nominados recebem a certificação da UNESCO com o título de Patrimônio Documental da Humanidade.

Para seu funcionamento, foi desenvolvido um documento intitulado "Diretrizes para a salvaguarda do patrimônio documental", responsável por determinar a forma de atuação do programa, seus objetivos, visão, missão, conceitos e obtenção de resultados (EDMONDSON, 2002).

O MOW foi criado após a identificação da considerável perda de documentos que se acumulava ao longo do tempo por falta de atenção e de recursos aos acervos documentais em várias regiões do mundo. Os objetivos do programa são:

(a) Facilitar a preservação do patrimônio documental mundial mediante as técnicas mais adequadas (...). (b) Facilitar o acesso mundial ao patrimônio documental (...). (c) Criar uma maior consciência em todo o mundo da existência e importância do patrimônio documental (...). (EDMONDSON, 2002, p. 6).

Assim como qualquer programa, é necessário que se estabeleça limites e definições da área de abrangência ${ }^{8}$, e o documento conceitua a Memória do Mundo da seguinte forma:

A Memória do Mundo é a memória coletiva e documentada dos povos do mundo - seu patrimônio documental - que, por sua vez, representa boa parte do patrimônio cultural mundial. Ela traça a evolução do pensamento, dos descobrimentos e das realizações da sociedade humana. É o legado do passado para a comunidade mundial presente e futura. (EDMONDSON, 2002, p. 5, grifo do autor).

É importante notarmos que o programa insere, claramente, o patrimônio documental como parte do patrimônio cultural mundial. Mais à

\footnotetext{
${ }^{7}$ Memory Of World, no original em inglês.

${ }^{8}$ O Programa Memória do Mundo identifica seu objeto de atuação, o patrimônio documental, com o requisito de se encaixar aos seguintes elementos: devem ser movíveis; feitos de símbolos/códigos, sons e/ou imagens; preserváveis; reproduzíveis e transladáveis; e fruto de um processo de documentação deliberado (EDMONDSON, 2002: 11)
} 
frente, no item 2 deste mesmo documento, encontramos outro trecho que relaciona o patrimônio documental ao patrimônio arquitetônico e aos lugares:

O Programa Memória do Mundo se baseia na suposição de que alguns itens, coleções, acervos ou fundos de patrimônio documental formam parte da herança mundial, à semelhança dos lugares de notável valor universal incluídos na Lista do Patrimônio Mundial da UNESCO. Considera-se que sua importância transcende os limites do tempo e da cultura, e que devem ser preservados para as gerações atuais e futuras e serem postos de alguma forma à disposição de todos os povos do mundo. (EDMONDSON, 2002, p. 8)

Notamos que as Diretrizes salientam a importância de uso destes bens por meio de alguma forma de disponibilização, seguindo princípios norteadores aplicados aos lugares e edificações.

Os documentos são historicamente constituídos como relevantes fontes de informação e colaboram significativamente com pesquisas históricas ao se mostrarem como a fonte primária de informação. Este uso está na própria função de ser do documento de arquivo. Seria ele suficiente para atender à demanda criada com o status de patrimônio?

A colaboração trazida à memória pelos documentos históricos é, como vimos com Le Goff, principalmente pela crítica ao documento. Quando inquirido, corresponde com a apresentação de respostas, ou indícios, que mostrem o caminho a ser percorrido. Mas, assim como os objetos, monumentos, monumentos históricos e lugares, é necessário que exista um discurso capaz de inseri-lo no contexto histórico. Como diz Chagas:

Para além da identificação de dados intrínsecos (tais como peso, dureza, forma, cor, textura, etc.) e de dados extrínsecos de ordem cultural (tais como função, valor estético, valor histórico, valor financeiro, valor simbólico, valor científico, etc.) o importante é compreender que uma coisa ou objeto só se transforma em bem cultural quando alguém (indivíduo ou coletividade), por ato de vontade afirma, descreve e garante a sua passagem simbólica para uma nova condição. A constituição do bem cultural implica um processo de atribuição voluntária de significados e valores. (2002, p. $144-145)$.

Assim como os monumentos históricos ${ }^{9}$, os documentos - em toda sua complexidade - não são criados para a memória, sendo a razão de sua gênese a realização de alguma atividade necessária ao seu órgão produtor. A patrimonialização corresponde a um processo de ressignificação do documento. Como tal, é necessário um discurso instituinte que o transfigure de documento a patrimônio. O Programa

\footnotetext{
9 Buscamos aqui a diferenciação entre monumento e monumento histórico apresentada por Choay (2001, p. 25-26): "[...]o monumento é uma criação deliberada (gewollte) cuja destinação foi pensada a priori, de forma imediata, enquanto o monumento histórico não é, desde o princípio, desejado (ungewollte) e criado como tal; ele é constituído a posteriori, pelos olhares convergentes do historiador e do amante da arte, que o selecionam da massa dos edifícios existentes, dentre os quais os monumentos representam apenas uma pequena parte. Todo objeto do passado pode ser convertido em testemunho histórico sem que para isso tenha tido, na origem, uma destinação memorial".
} 
Memória do Mundo detém poder e competência legal para tal ação, à semelhança de legislações culturais e demais entidades preservacionistas (UNESCO, IPHAN, etc.). No entanto, qual é a efetividade desta ressignificação para os documentos frente aos patrimônios arquitetônicos?

\section{Fundo NovaCap e Brasília: relação complementar}

Em outubro de 1987, o International Council on Monuments and Sites (ICOMOS) emite o seu relatório a respeito da indicação para inserção do Plano Piloto da cidade de Brasília, capital do Brasil construída no final da década de 1950, junto à Lista do Patrimônio da Humanidade, da UNESCO, responsável por eleger e tombar os principais patrimônios da cultura mundial (ICOMOS, 1987).

Após analisar o histórico da cidade, sua estrutura, formação e processo de construção, o parecer do ICOMOS foi favorável à inscrição do Plano Piloto de Brasília na Lista. Como está no relatório, a condição do desenvolvimento da cidade é um ato realmente digno de honras, por ser uma cidade construída diretamente do chão, em uma região onde não havia nada além de árvores e terra (ICOMOS, 1987).

Além deste fator, a própria estrutura desenvolvida por Lúcio Costa para o projeto da cidade é considerada como elemento de relevante importância, se mostrando, atualmente, como um marco na história da arquitetura mundial. Como aponta o relatório: "The 'pilot plan' that Costa drew up for Brasília was one of great expression power." (ICOMOS, 1987, p. 2).

Para que se realizasse a construção da cidade, o então Presidente do Brasil, Juscelino Kubitschek criou a Companhia Urbanizadora da Nova Capital (NovaCap), para que tomasse a frente neste empreendimento de construção da nova capital do Brasil.

Em 2007, o Programa Memória do Mundo, em seu nível nacional, nomina o arquivo da NovaCap como um conjunto do Patrimônio Documental do Brasil, por sua riqueza informativa e inestimável valor para a memória da nação brasileira, conforme registro na Portaria No 60, de 31 de outubro de 2007, do Ministério da Cultura ${ }^{10}$.

Em seu projeto de indicação, o Arquivo Público do Distrito Federal, detentor do fundo NovaCap e proponente da nominação, exalta a qualidade informativa do conjunto documental composto pelo arquivo da Companhia responsável pela construção da cidade reconhecida como Patrimônio da Humanidade (ARQUIVO PÚBLICO DO DISTRITO FEDERAL, 2007).

Seu acervo conta com documentação de 1892 a 1980, por considerar que o projeto de transferência da capital do país para o centro do território nacional não foi original do Presidente Kubitschek, mas vinha desde o final do século XIX. A documentação que pertenceu às equipes anteriores à NovaCap foi incorporada neste escopo documental que inclui todo o processo de idealização e construção da cidade.

\footnotetext{
${ }^{10}$ Disponível em: http://mow.arquivonacional.gov.br/images/pdf/PortariaMinC61 regulamentoMOWBrasil.pdf
} 
Considerando as proporções do evento de produziu este acervo, as relevâncias científicas, técnica e social são justificativas de conceder-lhe uma proteção especial. Trata-se da construção de uma cidade, idealizada, planejada e erguida a partir de apenas uma ideia. As estratégias utilizadas para atingir este objetivo, os meios que se seguiram, a movimentação que gerou no país, seja a de pessoas, com a migração do litoral para a região centro-oeste do país, seja a movimentação ideológica necessária entre a população, bem como a movimentação financeira e de recursos diversos. Isso se mostra relevante para o entendimento do desenvolvimento da política nacional, dos trabalhos sociais e de habitação ocorridos na época da migração, até mesmo por capacitações técnicas, como sistemas de construção civil, técnicas de arquitetura e urbanismo, as expedições realizadas para definição do terreno que serviria de base para 0 crescimento da cidade, entre diversos outros fatores.

Segundo o projeto de inscrição do Fundo NovaCap:

O Fundo NovaCap registra a Odisséia [sic] da construção da nova capital do Brasil, desde os estudos que a antecederam até sua inauguração. Os documentos que pertencem a esse fundo documental permitem-nos reconstituir a história da construção de Brasília, desde o seu plano de urbanismo e sua arquitetura às técnicas de construção, seus gênios criadores, candangos, personalidades ou não, que construíram a nova capital. (ARQUIVO PÚBLICO DO DISTRITO FEDERAL, 2007, p. 26)

Podemos compreender Brasília, enquanto Patrimônio da Humanidade, e o Fundo NovaCap, enquanto Patrimônio Documental, como elementos de um único complexo; um empreendimento que foi levado a termo, sendo que no elemento inscrito na Lista dos Patrimônios da Humanidade, encontramos o resultado final deste empreendimento, 0 produto obtido após uma jornada que se torna marco na história do Brasil, da arquitetura e do urbanismo mundiais. Já no elemento nominado como Patrimônio Documental do Brasil, encontramos o processo e os procedimentos responsáveis por levar a termo este projeto tão particular.

Neste sentido, a atuação dos dois patrimônios, cada qual em seu âmbito, tem como possibilidade se inter-relacionarem e se complementarem; um apresenta 0 projeto e o processo, o outro apresenta o produto. Para além da monumentalidade apresentada pela cidade em si, existe também a monumentalidade de informações apresentadas no conjunto documental que acompanhou seu desenvolvimento.

Para pensarmos nos efeitos gerados pelo reconhecimento de ambos os conjuntos, o urbanístico e o documental, atualmente Brasília é conhecida mundialmente e recebe grande número de visitantes para conhecer este empreendimento da construção civil digno de admiração e observação. Quanto ao Fundo NovaCap, assim como antes do registro Memória do Mundo e do reconhecimento como patrimônio documental, recebe como principais "visitantes" pesquisadores, acadêmicos, cientistas das áreas de História, Arquitetura e Urbanismo, entre outras áreas do 
conhecimento que podem se sentir beneficiados com a análise desse material para a realização de seus estudos.

\section{Conclusão}

Com este trabalho buscamos identificar o locus dos documentos no universo patrimonial, dominado por monumentos arquitetônicos, obras de arte notáveis e paisagens exuberantes e de notável beleza.

Como colocado no relatório da reunião de Quito, a população contemporânea é mais visual do que literária, privilegiando a disseminação do patrimônio arquitetônico e natural, o estímulo para observá-lo, admirá-lo e por fim, comprar as lembranças do lugar visitado. Este estímulo ao visual/estético gera um deslocamento do sentido simbólico ao sentido mercadológico do patrimônio e inibe a possibilidade de novas estratégias que visem a aproximação entre a sociedade em geral e os documentos históricos.

Ao longo do trabalho, algumas questões ficaram em aberto. Vimos que o entendimento que se tem de patrimônio documental atualmente está relacionado de forma muito próxima com o conceito de documentos históricos, ou arquivos permanentes. Como Rousseau e Couture analisaram, de toda a massa documental produzida pela sociedade, apenas uma pequena parcela é destinada à preservação histórica por assumir o caráter informativo e valor de testemunho do passado. Mas, podemos pensar, tudo o que restar do processo de avaliação e seleção será considerado patrimônio documental?

É difícil tecer alguma resposta definitiva para esta questão, mesmo se relacionarmos com os conceitos de patrimônio histórico e cultural tratados no início do trabalho. Choay nos mostra que o conceito de patrimônio histórico designa aquilo que é produto da sociedade, seu savoir-faire, e que é deixado para as futuras gerações. Pensando por essa ótica, sim, tudo o que restar do sistema documental social será considerado patrimônio, pois, além de serem eles os registros de informações derivadas da sociedade e das ações de homens e mulheres, 0 que resta é uma quantidade irrisória em relação ao que é produzido.

Se pensarmos na necessidade de consumo dos bens patrimoniais estabelecida pelos poderes, podemos considerar que os documentos talvez não atinjam a expectativa, no sentido que não são utilizados pelo turismo, da mesma forma que não são considerados como fetiche de valor mercadológico a ser comercializado. Por esta ótica, talvez nem tudo o que restar como espólio documental da sociedade será considerado patrimônio documental, com exceção, talvez, de documentos dotados de extrema beleza, como grandes mapas antigos e demais documentos cartográficos, que podem atrair a atenção de observadores curiosos por seus traços e estilos "exóticos". Um entendimento de documento mais próximo da concepção de objeto museológico e que não responde nossas questões.

Como o exemplo apresentado nos mostrou, da relação existente entre Brasília e o Fundo NovaCap, ambos são considerados patrimônios culturais, cada um com funções bastante particulares. Brasília tem a 
função de ser mostrada; Fundo NovaCap tem função de ser estudado. Brasília já nasceu monumental, o reconhecimento e a inscrição na Lista de Patrimônios da Humanidade somente autorizaram a realização de um trabalho mais apurado de publicidade e reforçaram o valor e o status histórico e patrimonial dado há muito para a cidade. O Fundo NovaCap nasceu como suporte documental à realização de Brasília, após a inscrição como Patrimônio Documental, continuou a ser suporte de Brasília, mas de outra forma, sendo agora suporte para a memória de um lugar que é marco na história do Brasil, função essa que, de fato, já era realizada pelo fundo desde sua incorporação ao acervo do Arquivo Público do Distrito Federal.

A efetividade da ressignificação do documento à qualidade de patrimônio não é perceptível dentro dos atuais traços conferidos pela modernidade à instituição "Patrimônio", limitando-se a garantir a preservação física do referido conjunto documental. Diferente dos patrimônios arquitetônicos, a informação - conteúdo e essência do documento - não pode ser-lhe extraída ou inibida em favor de uma fetichização mercadológica, sob a pena da definitiva destruição do documento.

Lage nos colocou uma questão fundamental ao relacionar utilidade e conhecimento no patrimônio. As políticas culturais e legislações modernas converteram os patrimônios em mercadoria ao associar-lhes a ideia de utilidade e deslocar a um papel secundário sua essência simbólica de transmissão e permanência de memórias e identidades coletivas. Nos termos da visão moderna de patrimônio, esta "utilidade" pode não se encaixar muito bem ao patrimônio documental.

Com improvável valor de culto, de exibição e uma difícil fetichização, os documentos, ao serem ressiginificados à qualidade de patrimônio, mantêm o seu caráter instrumental ao servirem de fontes históricas. A patrimonialização de documentos, nos moldes modernos, não modifica seu status social, mas reforça a sua conexão ao conceito primeiro de monumento: memorar, advertir, fazer lembrar.

\section{Referências}

ARQUIVO PÚBLICO DO DISTRITO FEDERAL. Candidatura do Fundo NovaCap ao Registro Memória do Mundo, 2007, Não publicado.

BRASIL. Constituição da República dos Estados Unidos do Brasil de 16 de julho de 1934. Disponível em:

http://www.planalto.gov.br/ccivil 03/constituicao/constituicao34.htm.

Acesso em: 14 set. 2017.

BRASIL. Constituição dos Estados Unidos do Brasil de 18 de setembro de 1946. Disponível em:

http://www.planalto.gov.br/ccivil_03/constituicao/constituicao46.htm.

Acesso em: 14 set. 2017. 
BRASIL. Constituição da República Federativa do Brasil de 1967. Disponível em:

http://www.planalto.gov.br/ccivil 03/constituicao/constituicao67.htm. Acesso em: 14 set. 2017.

BRASIL. Constituição da República Federativa do Brasil de 1988. Disponível em:

http://www.planalto.gov.br/ccivil 03/constituicao/constituicaocompilado.h tm. Acesso em: 14 set. 2017.

BRASIL. Decreto Lei no 25, de 30 de novembro de 1937. Organiza a proteção do patrimônio histórico e artístico nacional. Disponível em: http://www.planalto.gov.br/ccivil 03/decreto-lei/Del0025.htm. Acesso em: 14 set. 2017.

BRIET, Suzanne. Qu'est-ce que la documentation? Paris: Édit - Éditions Documentaires Industriales et Techniques, 1951. 48 p. Disponível em: http://martinetl.free.fr/suzannebriet/questcequeladocumentation/briet.pdf . Acesso em: 14 set. 2017.

CAMARGO, Célia Reis. À margem do patrimônio cultural. Estudo sobre a rede institucional de preservação do patrimônio histórico no Brasil (1838 1980). 1999. 173 f. Tese (Doutorado em História)- Universidade Estadual Paulista (UNESP), Assis, 1999.

CASTRIOTA, Leonardo Barci. Patrimônio Cultural: Conceitos, políticas, instrumentos. São Paulo: Annablume, 2009.

CHAGAS, Mário. Cultura, patrimônio e memória. In: INTEGRAR Congresso Internacional de Arquivos, Bibliotecas, Centros de Documentação e Museus,1. Textos. São Paulo: FEBAB, 2002. p. 135-150.

CHOAY, Françoise. A alegoria do patrimônio. São Paulo: Estação Liberdade: Editora UNESP, 2001.

CRIVELLI, Renato; BIZELLO, Maria Leandra. Patrimônio, documentos, informação. IBERSID: revista de sistemas de información y documentación, Zaragoza, V. 6, p. 173-178, 2012. Disponível em: https://www.ibersid.eu/ojs/index.php/ibersid/article/view/3990. Acesso em: 17 jun. 2019.

CRIVELLI, Renato. A patrimonialização do arquivo pessoal: Análise dos Registros Memória do Mundo do Brasil, da UNESO. 2013. 222 f. Dissertação (Mestrado em Ciência da Informação)- Universidade Estadual Paulista (UNESP). Marília, 2013.

EDMONDSON, Ray. Memória do Mundo: Diretrizes para salvaguarda do patrimônio documental. Paris: UNESCO, 2002. Disponível em:

http://mow.arquivonacional.gov.br/images/pdf/Diretrizes para a salvagu arda do patrim\%C3\%B4nio documental.pdf. Acesso em: 14 set. 2017.

GARCIA BELSUNCE, C. A. Legislação sobre proteção do patrimônio documental e cultural. Acervo, Rio de Janeiro. v. 1, n. 1 p. 29-40, jan.jun. 1986. 
GONÇALVES, José Reginaldo S. O patrimônio como categoria de pensamento. In: ABREU, Regina, CHAGAS, Mário (Org). Memória e Patrimônio: ensaios contemporâneos. 2.ed. Rio de Janeiro: Lamparina, 2009, p. 25-33.

GONÇALVES, José Reginaldo Santos. A retórica da perda: os discursos do patrimônio cultural no Brasil. Rio de Janeiro: Ed. UFRJ/MinC - IPHAN, 1996.

HALBWACHS, Maurice. A Memória Coletiva. São Paulo: Vértice, 1990. ICOMOS. Advisory body evaluation. 1987. Disponível em: http://whc.unesco.org/en/list/445/documents/\%23ABevaluation. Acesso em: 14 set. 2017.

LAGE, Maria Otília Pereira. Abordar o Património Documental: Territórios, Práticas e Desafios. Guimarães: Éden Gráfico, 2002. (Cadernos NEPS, 4)

LE GOFF, Jacques. Documento/Monumento. In: História e memória. 7.ed. Campinas: Ed. UNICAMP, 2013, p. 485-498.

ORGANIZAÇÃO dos Estados Americanos (OEA). Normas de Quito. 1967. Disponível em:

http://portal.iphan.gov.br/uploads/ckfinder/arquivos/Normas\%20de\%20Q uito\%201967.pdf. Acesso em: 14 set. 2017.

ORTEGA, Cristina Dotta; LARA, Marilda Lopes Ginez de. A noção de documento: De Otlet aos dias de hoje. DataGramaZero - Revista de Ciência da Informação, v. 11, n. 2, abr. 2010.

OTLET, Paul. Documentos e documentação. In: CONGRESSO DE DOCUMENTAÇÃO UNIVERSAL. Paris. 1937. [Discursos...] Rio de Janeiro: Imprensa Nacional, 1947. Separata. Disponível em: http://www.conexaorio.com/biti/otlet. Acesso em: 14 set. 2017.

POLLAK, Michael. Memória e identidade social. Estudos Históricos, Rio de Janeiro, vol. 5, n. 10, 1992, p. 200-212.

RODRIGUES, Marly. Preservar e consumir: o patrimônio histórico e o turismo. In: FUNARI, Pedro Paulo, PINSKY, Jaime (Org.). Turismo e patrimônio cultural. São Paulo: Contexto, 2002, p. 15-24.

ROUSSEAU, Jean Yves, COUTURE, Carol. Os fundamentos da disciplina arquivística. Lisboa: Dom Quixote, 1998.

THIESEN, Icléia. Memória institucional. João Pessoa: Editora da UFPB, 2013.

VELOSO, Mariza. O fetiche do patrimônio.HABITUS, Goiânia, v. 4, n.1, jan./jun. 2006, p. 437-454. 